\title{
New low-dose liquid pilocarpine formulation for treating dry mouth in Sjögren's syndrome: clinical efficacy, symptom relief, and improvement in quality of life
}

Machiko Watanabe ${ }^{1 *}$, Chisato Yamada ${ }^{1}$, Yoshinori Komagata ${ }^{2,3}$, Hirotoshi Kikuchi $^{2}$, Hiroyuki Hosono ${ }^{1}$ and Fumio Itagaki $^{1}$

\begin{abstract}
Background: Patients with Sjögren's syndrome (SS) typically present clinically with xerostomia (dry mouth) because of progressive damage to the exocrine glands. We developed a new, low-dose pilocarpine/sodium alginate (LPA) solution with pilocarpine hydrochloride to inhibit systemic adverse effects by administering via the oral mucosa. The purpose of this study was to assess its stability, safety, and efficacy.

Methods: The pilocarpine concentration in an LPA liquid formulation was measured 3, 7, 14, and 28 days after preparation to assess its stability. A prospective clinical trial was undertaken to assess the efficacy and safety of the LPA solution as a symptomatic treatment for dry mouth in SS. Patients $(n=24)$ with clinically significant xerostomia were enrolled after providing written informed consent. Whole-mouth salivary flow rate was measured twice; immediately before and 60 min after LPA application. Symptoms were assessed by questionnaire with visual analog scales or checkboxes before the first application (baseline), and then once daily for 7 days.

Results: The pilocarpine content 3, 7, 14, and 28 days after preparation showed no marked change, confirming its stability. Salivary flow was significantly increased from $0.076 \pm 0.092 \mathrm{~g} / 30 \mathrm{~s}$ to $0.122 \pm 0.140 \mathrm{~g} / 30 \mathrm{~s} 60 \mathrm{~min}$ after LPA administration $(P<0.001)$. Dry mouth and thirstiness showed significant improvement compared with that of baseline $(P \leq 0.01)$. The only adverse effect was sweating, and no serious drug-related adverse events were reported.

Conclusions: This new, low-dose pilocarpine formulation was well-tolerated and resulted in significant improvements in symptoms of dry mouth and other xerostomic conditions in patients with SS.
\end{abstract}

Trial registration: The study approval number in the institution; 08-068-2. Registered January 19, 2009. UMIN000029307. Registered 27 September 2017 (retrospectively registered).

Keywords: Sjögren's syndrome, Pilocarpine, Xerostomia, Dry mouth, Sodium alginate

\footnotetext{
* Correspondence: wmachiko@pharm.teikyo-u.ac.jp

${ }^{1}$ Laboratory of Clinical Pharmaceutics, Faculty of Pharma-Science, Teikyo

University, 2-11-1 Kaga, Itabashi-ku, Tokyo 173-8605, Japan

Full list of author information is available at the end of the article
} 


\section{Background}

Sjögren's syndrome (SS), a chronic autoimmune disease with slow progression, is characterized by lymphocytic infiltration into the exocrine glands, resulting in xerostomia. As a result of exocrine dysfunction, most patients with SS have symptoms related to diminished activity of the salivary glands, which can cause difficulty chewing and swallowing food and speaking without frequent water intake [1]. Moreover, the chronicity of the disease can lead to significant debility and decreased patient quality of life [2, 3].

Pilocarpine is a parasympathomimetic agent that functions primarily as a muscarinic agonist with mild $\beta$ adrenergic activity. This alkaloid causes pharmacologic stimulation of exocrine glands in humans, resulting in diaphoresis, salivation, lacrimation, and gastric and pancreatic secretion. Although pilocarpine hydrochloride tablets are currently indicated for the treatment of xerostomia in SS, their toxicity is frequently reported $[4,5]$.

We developed a new, low-dose pilocarpine formulation of a pilocarpine/sodium alginate (LPA) solution. In previous reports, we demonstrated that sodium alginate (Alg-Na) is effective for retention of moisture in the mouth of patients with xerostomia [6,7]. We, therefore, hypothesized that Alg-Na would be helpful in alleviating symptoms of xerostomia and would provide a useful base for the pilocarpine formulation. As a medium, Alg$\mathrm{Na}$ was used in the low-dose pilocarpine formulation to inhibit systemic adverse effects.

After investigating the stability of the LPA solution, a prospective clinical trial was undertaken to assess its efficacy and safety as a symptomatic treatment for dry mouth in SS. Herein, we present the results of that clinical trial.

\section{Methods}

\section{Preparation}

Pilocarpine, Alg- $\mathrm{Na}$, and sodium bicarbonate $\left(\mathrm{NaHCO}_{3}\right)$ were purchased from Wako Pure Chemical Industries (Osaka, Japan). LPA solution (0.3\% pilocarpine, 1\% Alg$\mathrm{Na}$, and $0.1 \% \mathrm{NaHCO}_{3}, w / v$ ) was prepared as follows. Pilocarpine was completely dissolved in $0.1 \%(\mathrm{w} / \mathrm{v})$ paraben solution, and $1.0 \mathrm{~g}$ Alg-Na was added. Citric acid monohydrate $(0.12 \mathrm{~g}), 1.1 \mathrm{~g}$ trisodium citrate dihydrate, and $0.1 \mathrm{~g} \mathrm{NaHCO}$ were added to make a final volume of $100 \mathrm{~mL}$ ( $\mathrm{pH}$ 6.2). The LPA solution was packaged in Hybripack $^{\odot}$ tubes $(0.32 \mathrm{~mL}$, pilocarpine $0.96 \mathrm{mg})$. The dose volume was determined by estimating a single, well-spread application to the entire oral mucosa.

\section{Stability}

Preparations were placed in light-blocking bags and stored at $4{ }^{\circ} \mathrm{C}$. Pilocarpine content was determined 0,3 , 7,14 , and 28 days after preparation by high-performance
Table 1 Characteristics of patients with Sjögren's syndrome and dry mouth

\begin{tabular}{|c|c|}
\hline Number of patients (male / female) & $24(0 / 24)$ \\
\hline Average age (years) $^{a}$ & $61.8 \pm 13.4$ \\
\hline Salivary secretion $(\mathrm{g} / 30 \mathrm{s.})^{a}$ & $0.076 \pm 0.092$ \\
\hline \multicolumn{2}{|l|}{ Major complications (cases) } \\
\hline Osteoporosis & 10 \\
\hline Rheumatism & 7 \\
\hline Hypertension & 7 \\
\hline Refractory gastroesophageal reflux disease & 6 \\
\hline Keratitis & 6 \\
\hline Diabetic & 5 \\
\hline Hyperlipidemia & 5 \\
\hline Systemic scleroderma & 4 \\
\hline Insomnia & 4 \\
\hline \multicolumn{2}{|l|}{ Clinical laboratory tests } \\
\hline \multicolumn{2}{|l|}{ Anti-SS-A ${ }^{\text {b }}$ antibody (cases) } \\
\hline$>5 \mathrm{U} / \mathrm{mL}$ & 17 \\
\hline$<5 \mathrm{U} / \mathrm{mL}$ & 7 \\
\hline \multicolumn{2}{|l|}{$\operatorname{lgG}$ (cases) } \\
\hline$<800 \mathrm{mg} / \mathrm{dL}$ & 2 \\
\hline $800-1700 \mathrm{mg} / \mathrm{dL}$ & 9 \\
\hline$>1700 \mathrm{mg} / \mathrm{dL}$ & 11 \\
\hline Serum creatinine $(\mathrm{mg} / \mathrm{dL})^{\text {a }}$ & $0.75 \pm 0.24$ \\
\hline Blood urea nitrogen $(\mathrm{mg} / \mathrm{dL})^{a}$ & $14.6 \pm 4.6$ \\
\hline Aspartate aminotransferase $(\mathrm{U} / \mathrm{L})^{a}$ & $23 \pm 11$ \\
\hline Alanine aminotransferase (U/L) ${ }^{a}$ & $17 \pm 7$ \\
\hline
\end{tabular}

: Where indicated, data are expressed as means \pm SD

b: Anti-Sjögren's syndrome-related antigen A

liquid chromatography (HPLC) using an absolute calibration curve method. Samples were diluted 5000-fold with Milli-Q ${ }^{\circ}$ water before being applied to the HPLC column. HPLC conditions, with a minor change from previous reports $[8,9]$, were as follows: column-oven temperature, $50{ }^{\circ} \mathrm{C}$; mobile phase, $0.05 \mathrm{M}$ potassium dihydrogen phosphate/methanol $(95 / 5, v / v)$; and mobile phase flow rate, $1.0 \mathrm{~mL} / \mathrm{min}$. The eluate from the HPLC

Table 2 Stability test of pilocarpine solution filled in a Hybripack ${ }^{\circledast}$ tube

\begin{tabular}{lll}
\hline Time (day) & Pilocarpine concentration $(\mu \mathrm{g} / \mathrm{mL})^{\text {a }}$ & Residual (\%) \\
\hline 0 & $0.56 \pm 0.03$ & 100 \\
3 & $0.52 \pm 0.02$ & 92.8 \\
7 & $0.59 \pm 0.01$ & 105.3 \\
14 & $0.55 \pm 0.02$ & 98.4 \\
28 & $0.55 \pm 0.01$ & 98.6
\end{tabular}

$a_{\text {: }}$ Data are expressed as means \pm SD $(n=3)$ 


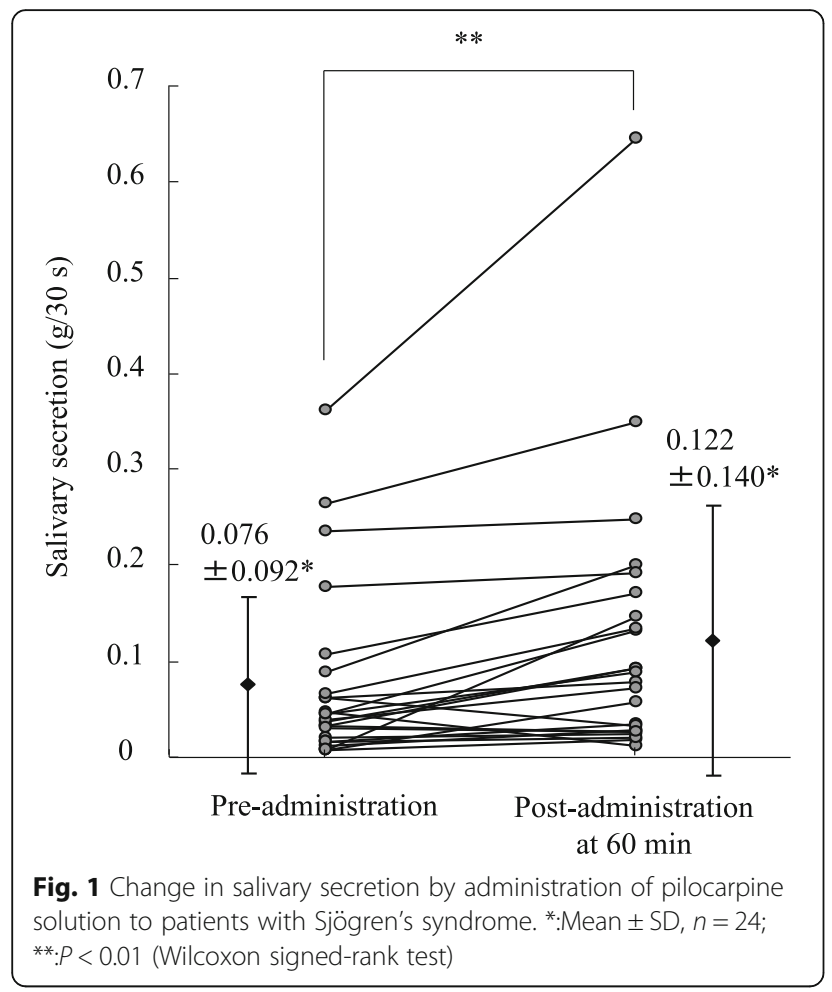
**:P $<0.01$ (Wilcoxon signed-rank test) column was monitored for pilocarpine using an ultraviolet detector $(\lambda=214 \mathrm{~nm})$.

\section{Patients}

Approval was granted by the Teikyo University School of Medicine Ethics Committee. After the purpose and procedures of the study were explained in writing, written informed consent was obtained from all participants. Female SS patients $(n=24)$ with dry mouth (mean age, $61.8 \pm 13.4$ years) who visited the Internal Medicine Department of Teikyo University Hospital were enrolled. Their characteristics are shown in Table 1.

\section{Assessment}

A 10-cm visual analog scale (VAS; from "not at all uncomfortable" to "unbearably uncomfortable") was used to assess the following five items representing intraoral conditions: "dryness", "thirstiness", "stickiness", "altered taste", and "painful tongue". A 5-cm VAS was used to assess six items representing the following aspects of quality of everyday life: "general activities", "normal work", "interpersonal relationships", "food intake", "sleep" (from "sleep very well" to "cannot sleep at all"), and "appetite" (from "very good" to "completely diminished"). The 5-cm VAS ranged from "having no difficulty" to "having great difficulty", unless otherwise specified. A 5-point scale ("better", "slightly better",

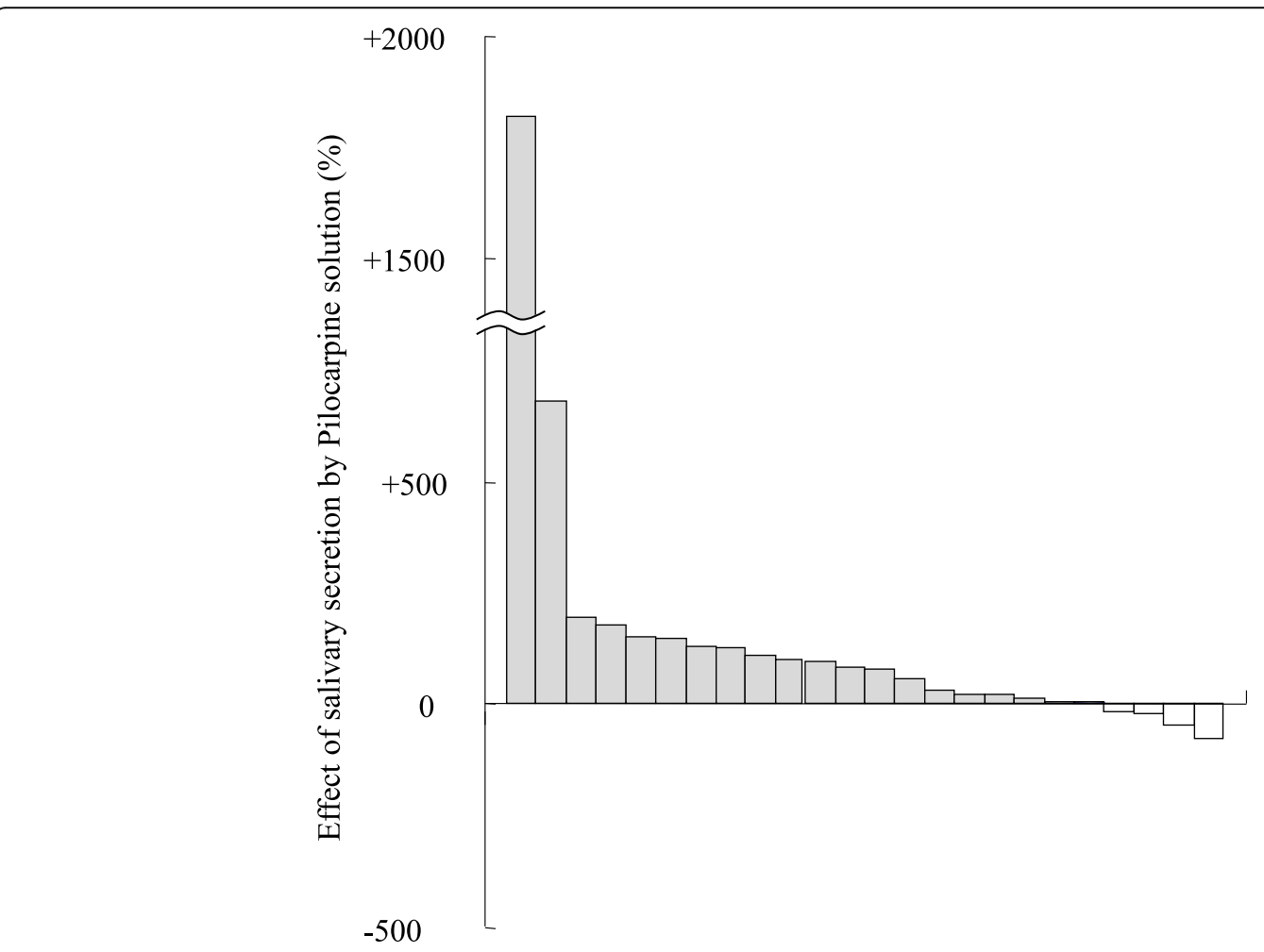

Fig. 2 Salivary secretion after administration of pilocarpine solution to individual patients with Sjögren's syndrome. Average $163 \pm 381 \%, n=24$ 
Table 3 Self-reported oral effects of administration of pilocarpine solution to patients with Sjögren's syndrome

\begin{tabular}{llll}
\hline Item & & VAS $(10 \mathrm{~cm})^{\mathrm{b}}$ & \\
\hline Dryness & Pre-administration & Post-administration at 60 min & $3.7(2.0,6.9)^{a}$ \\
Thirstiness & $7.1(6.1,8.0)$ & $4.4(2.2,6.5)^{a}$ & $2.4(1.5,5.3)^{a}$ \\
Stickiness & $6.3(4.5,7.9)$ & $2.3(0.7,5.4)^{a}$ & $2.4(0.9,6.5)$ \\
Altered taste & $6.3(4.8,7.4)$ & $4.0(0.7,5.4)$ & $1.4(0.5,3.2)$ \\
Painful tongue & $0.5(0.3,4.3)$ & $1.1(0.5,4.3)$ & $2.2(0.4,7.0)$ \\
\hline
\end{tabular}

a: Significantly different from pre-administration at $P<0.05$ (Scheffe's $\mathrm{F}$ test) $(n=21)$

bAS, visual analog scale; Median (1st quartile, 3rd quartile)

"unchanged", "slightly worse", and "worse") was used to assess overall changes in symptoms. Salivary flow was evaluated by measuring the amount of saliva absorbed into cotton rolls in $30 \mathrm{~s}$.

\section{Treatment protocol}

Prior to administering the LPA liquid formulation, participants were assessed for intraoral conditions, quality of everyday life, and salivary flow. The following instructions were given to participants before the first dose: 1) avoid swallowing and spread the liquid formulation thoroughly over the oral mucosa; 2) spit any remaining liquid 5 min after administration; and 3) avoid eating, drinking, and rinsing the mouth for 60 min after administration, or until salivary flow has been measured. For continuous LPA administration, participants were instructed to use one tube three times daily with doses $4 \mathrm{~h}$ apart for seven days and to follow instructions 1) and 2) above. Participants were asked to complete the assessment for changes in symptoms, intraoral conditions, side effects, and everyday life after completing the seven-day LPA course or terminating the course for any reason.

\section{Saliva collection}

We used cotton rolls with a 1-cm diameter and a standardized 3-cm major axis. We first measured the weight

Table 4 Effect on daily activities following administration of pilocarpine solution to patients with Sjögren's syndrome

\begin{tabular}{lll}
\hline Item & \multicolumn{2}{l}{ VAS $(5 \mathrm{~cm})^{\text {a }}$} \\
\cline { 2 - 3 } & Pre-administration & $\begin{array}{l}\text { Continuous } \\
\text { administration }\end{array}$ \\
\hline General activities $(n=21)$ & $2.4(1.2,3.3)$ & $1.0(0.3,2.0)^{* *}$ \\
Normal work $(n=21)$ & $2.4(1.0,3.4)$ & $1.0(0.4,2.1)$ \\
Interpersonal relationships & $2.4(1.5,3.2)$ & $1.4(0.7,2.4)^{* *}$ \\
$(n=20)$ & & $1.4(0.7,3.0)^{*}$ \\
Food intake $(n=18)$ & $2.6(1.0,4.0)$ & $1.5(0.7,2.5)$ \\
Sleep $(n=20)$ & $2.4(0.8,2.7)$ & $1.1(0.5,1.7)$ \\
Appetite $(n=20)$ & $0.9(0.6,2.4)$ & \\
\hline
\end{tabular}

*: Significantly different from pre-administration at $P<0.05$; ${ }^{* *}: P<0.01$ (Wilcoxon signed-rank test)

aVA, visual analog scale; Median (1st quartile, 3rd quartile) of the dry cotton rolls, and then subtracted this from the weight of the cotton rolls soaked with saliva produced after $30 \mathrm{~s}$.

\section{Statistical analysis}

Salivary secretion (salivary flow) results are expressed as means, while the results of VAS assessment are expressed as median scores (1st and 3rd quartiles). Scores for intraoral conditions were analyzed by Scheffe's F test; saliva flow measurements and scores for quality of everyday life were assessed using the Wilcoxon signed-rank test. Differences were deemed statistically significant at $P<0.05$.

\section{Results \\ Stability}

The pilocarpine concentration in the LPA liquid formulation $3,7,14$, and 28 days after preparation was $92.8 \%$, $105.3 \%, 98.4 \%$, and $98.6 \%$ of that measured immediately after preparation at baseline (Table 2), indicating no marked change in pilocarpine content for at least 4 weeks.

\section{Saliva collection}

The amount of saliva secreted 60 min after LPA administration $(0.122 \pm 0.140 \mathrm{~g} / 30 \mathrm{~s})$ was significantly higher than that measured before LPA administration (0.076 \pm $0.092 \mathrm{~g} / 30 \mathrm{~s})(P<0.01)$ (Fig. 1). Twenty participants $(83 \%)$ showed elevated salivary secretion after LPA

Table 5 Effect on experiences following administration of pilocarpine solution to patients with Sjögren's syndrome

\begin{tabular}{lll}
\hline Item & VAS $(5 \mathrm{~cm})^{a}$ & \\
\cline { 2 - 3 } & Pre-administration & Continuous administration \\
\hline Taste & $0.6(0.2,1.7)$ & $0.9(0.3,2.6)$ \\
Smell & $0.3(0.1,0.6)$ & $0.4(0.2,1.3)$ \\
Irritation & $0.4(0.1,0.6)$ & $0.4(0.2,1.3)$ \\
Touch & $0.4(0.1,1.7)$ & $0.4(0.2,1.2)$ \\
Ease of use & $2.4(0.7,3.5)$ & $1.3(0.8,3.1)$
\end{tabular}

${ }^{\mathrm{a}}$ VAS, visual analog scale; Median (1st quartile, 3rd quartile), $(n=21)$ 
Table 6 Effect on symptoms following administration of pilocarpine solution to patients with Sjögren's syndrome

\begin{tabular}{llllll}
\hline & Better & Slightly better & Unchanged & Slightly worse & Worse \\
\hline Post-administration at 60 min* $^{*}$ & $1(4.2 \%)$ & $17(70.8 \%)$ & $5(20.8 \%)$ & $0(0 \%)$ & $1(4.2 \%)$ \\
Continuous administration** $^{*}$ & $2(10.5 \%)$ & $8(42.1 \%)$ & $9(47.4 \%)$ & $0(0 \%)$ & $0(0 \%)$ \\
\hline
\end{tabular}

*: $n=24 ;{ }^{* *}: n=19$; values shown are number of individuals (percentage of total)

administration, albeit with noticeable individual variation in increments (Fig. 2).

\section{Assessment}

As shown in Table 3, the median VAS scores for "dryness", "thirstiness", and "stickiness in the mouth" were $>5$ before LPA administration, and these were reduced 60 min after the first dose of LPA and at the end of the 7-day LPA course (i.e., continuous LPA administration). In particular, post-administration (i.e., after the first dose and continuous administration) scores for "dryness" and "thirstiness" were significantly lower than the pre-administration scores $(P<0.05)$, suggesting good improvement.

Median VAS scores for all items representing quality of everyday life, except "appetite", were reduced after continuous LPA administration, indicating improvement following the treatment (Table 4). There were significant differences between pre- and post-administration scores for "general activities" $(P<0.01)$, "interpersonal relationships" $(P<0.01)$, and "food intake" $(P<0.05)$.

All median scores for items representing experience after LPA administration were $<2.5$; in particular, those for "taste", "smell", "irritation", and "touch" were low (<1.0) (Table 5).

Dry mouth symptoms were "better", "slightly better", and "unchanged" $60 \mathrm{~min}$ after the first dose of the LPA liquid formulation in 1,17 , and 5 participants, respectively, while symptoms were "worse" in 1 participant (Table 6). After continuous LPA administration, dry mouth symptoms were "better", "slightly better", and "unchanged" in 2, 8, and 9 participants, respectively (Table 6). One participant experienced slight hot flushes and flares after the initial dose and declined continuous LPA administration. Four participants experienced slight headache, dizziness, and hot flushes during continuous LPA administration.

\section{Discussion}

The pilocarpine content in the LPA liquid formulation was largely unchanged for 28 days after preparation in the dark at $4{ }^{\circ} \mathrm{C}$, indicating that the formulation is stable when stored in the test container under the test conditions. On the basis of these findings, each dose was individually packed in a Hybripack ${ }^{\circ}$ tube, and the expiration date under the specified conditions was labeled as " 28 days after preparation in dark and cool conditions".

The amount of saliva secreted increased significantly 60 min after LPA administration in SS patients with dry mouth. In addition, intraoral conditions and quality of everyday life were generally improved by continuous LPA administration. In particular, pre-administration and postadministration VAS scores for "dryness", "thirstiness", "general activities", "interpersonal relationships", and "food intake" differed significantly. These findings suggest that the increase in saliva secretion relieves dry mouth symptoms and alleviates conversation and eating difficulties, thereby improving the overall quality of everyday life. Furthermore, the 1\% Alg-Na content appeared to be effective for relieving dry mouth symptoms and for achieving favorable retention and spread of the formulation thoroughly within the oral cavity.

It has been reported that oral pilocarpine mouthwash, which can be used at lower doses than tablets with reductions in some adverse effects, was not superior to that of $0.9 \%$ saline at relieving subjective oral dryness [10-12]. While a high incidence of hyperhidrosis (40.6\%) is problematic in patients taking Salagen tablets, the incidence in the present study was low (1 participant, $4.2 \%)$. The following additional adverse events, albeit mild, were caused by the LPA formulation: hot flushes $(n=3)$, as well as headache, dizziness, abdominal pain, and rhinitis $(n=1$ each). Such adverse events are known in patients taking Salagen ${ }^{\circ}$ tablets.

This study contains limitations. First, we conducted the study using an open-label design with a small number of cases, which might have led to subjective bias. Especially, the self-reported data of the patients may have been affected by the design. Second, although we estimated the effectiveness of pilocarpine solution before and after administration, this study was a singlearm design. Nevertheless, taken together, the new LPA formulation (pilocarpine content, $0.96 \mathrm{mg}$ ) is potentially a superior alternative to Salagen ${ }^{\circ}$ tablets (pilocarpine content, $5 \mathrm{mg}$ ) for treating SS patients with dry mouth, and, in turn, improving their quality of life.

\section{Conclusions}

The new LPA formulation improved intraoral xerostomic conditions and quality of everyday life in SS patients with dry mouth through increasing saliva secretion.

\section{Abbreviations}

Alg-Na: Sodium alginate; HPLC: High-performance liquid chromatography; LPA: Low-dose pilocarpine/sodium alginate; SS: Sjögren's syndrome; VAS: Visual analog scale

Acknowledgements Not applicable. 


\section{Funding}

This study was supported by research funds from Teikyo University.

\section{Availability of data and materials}

All data generated or analyzed during this study are included in this published article.

\section{Authors' contributions}

MW conceived the study, designed the protocol and drafted the manuscript. $\mathrm{CY}, \mathrm{YK}, \mathrm{HK}, \mathrm{HH}$, and $\mathrm{Fl}$ carried out acquisition of the patient data. YK and $\mathrm{HK}$ monitored the patients. MW analyzed and interpreted the data. All authors revised and approved the final manuscript.

\section{Ethics approval and consent to participate}

This study was conducted with the approval of Teikyo University School of Medicine Ethics Committee (08-068-2). Written informed consent was obtained from all participants.

\section{Consent for publication}

Not applicable.

\section{Competing interests}

The authors declare that they have no competing interests.

\section{Publisher's Note}

Springer Nature remains neutral with regard to jurisdictional claims in published maps and institutional affiliations.

\section{Author details}

'Laboratory of Clinical Pharmaceutics, Faculty of Pharma-Science, Teikyo University, 2-11-1 Kaga, Itabashi-ku, Tokyo 173-8605, Japan. ${ }^{2}$ Department of Internal Medicine, Teikyo University School of Medicine, 2-11-1 Kaga, Itabashi-ku, Tokyo 173-8605, Japan. ${ }^{3}$ First Department of Internal Medicine, Kyorin University School of Medicine, 6-20-2 Shinkawa, Mitaka-shi, Tokyo 181-8611, Japan.

Received: 12 October 2017 Accepted: 28 January 2018

Published online: 01 March 2018

\section{References}

1. Delaleu N, Jonsson R, Koller MM. Sjögren's syndrome. Eur J Oral Sci. 2005; 113:101-13.

2. Stewart CM, Berg KM, Cha S, Reeves WH. Salivary dysfunction and quality of life in Sjögre'n syndrome: a critical oral-systemic connection. J Am Dent Assoc. 2008;139:291-9.

3. Rostron J, Rogers S, Longman L, Kaney S, Field EA. Health-related quality of life in patients with primary Sjögren's syndrome and xerostomia: a comparative study. Gerodontology. 2002:19:53-9.

4. Noaiseh G, Baker JF, Vivino FB. Comparison of the discontinuation rates and side-effect profiles of pilocarpine and cevimeline for xerostomia in primary Sjögren's syndrome. Clin Exp Rheumatol. 2014;32:575-7.

5. Nakamura N, Sasano N, Yamashita H, Igaki H, Shiraishi K, Terahara A Asakage T, Nakao K, Ebihara Y, Ohtomo K, Nakagawa K. Oral pilocarpine (5mg t.l.D.) used for xerostomia causes adverse effects in Japanese. Auris Nasus Larynx. 2009:36:310-3.

6. Shin M, Watanabe M, Yanagi M, Saito M, Nishizawa S, Chigono Y, Hirabayashi S, Matsuda J, Yamaoka K, Inoue K. Basic study on preparation of spray for alleviating dry mouth symptoms. J Pharm Health Care Sci. 2008;34: 240-5.

7. Shin M, Watanabe M, Yanagi M, Saito M, Nishizawa S, Chigono Y, Hirabayashi S, Matsuda J, Yamaoka K, Inoue K. Clinical evaluation of spray to alleviate symptoms of xerostomia (dry mouth). J Pharm Health Care Sci. 2008;34:246-51.

8. Rendi MA, Ellis PP, Gal J. High-performance liquid chromatographic assay for pilocarpine in aqueous humor. J Chromatogr. 1984;336:337-44.

9. Weaver ML, Tanzer JM, Kramer PA. High-performance liquid chromatographic determination of pilocarpine in plasma. J Chromatogr. 1992:581:293-6.

10. Bernardi R, Perin C, Becker FL, Ramos GZ, Gheno GZ, Lopes LR, Pires M, Barros HM. Effect of pilocarpine mouthwash on salivary flow. Braz J Med Biol Res. 2002;35:105-10
11. Kim JH, Ahn HJ, Choi JH, Jung DW, Kwon JS. Effect of $0.1 \%$ pilocarpine mouthwash on xerostomia: double-blind, randomised controlled trial. J Oral Rehabil. 2014;41:226-35

12. Tanigawa T, Yamashita J, Sato T, Shinohara A, Shibata R, Ueda H, Sasaki H. Efficacy and safety of pilocarpine mouthwash in elderly patients with xerostomia. Spec Care Dentist. 2015:35:164-9.

\section{Submit your next manuscript to BioMed Central and we will help you at every step:}

- We accept pre-submission inquiries

- Our selector tool helps you to find the most relevant journal

- We provide round the clock customer support

- Convenient online submission

- Thorough peer review

- Inclusion in PubMed and all major indexing services

- Maximum visibility for your research

Submit your manuscript at www.biomedcentral.com/submit 